\title{
Saliva as a first-line diagnostic tool: A spectral challenge for identification of cancer biomarkers
}

\author{
Czesława Paluszkiewicz a , Ewa Pięta ${ }^{\mathrm{a}, *}$, Monika Woźniak ${ }^{\mathrm{a}}$, Natalia Piergies ${ }^{\mathrm{a}}$, Anna Koniewska ${ }^{\mathrm{b}}$, \\ Wojciech Ścierski $^{\text {b }}$, Maciej Misiołek ${ }^{\mathrm{b}}$, Wojciech M. Kwiatek ${ }^{\mathrm{a}}$ \\ a Institute of Nuclear Physics Polish Academy of Sciences, PL-31342 Krakow, Poland \\ ${ }^{\mathrm{b}}$ Medical University of Silesia, Department of Otorhinolaryngology and Oncological Laryngology, PL-41800 Zabrze, Poland
}

\section{A R T I C L E I N F O}

Article history:

Received 15 October 2019

Received in revised form 5 March 2020

Accepted 20 March 2020

Available online 21 March 2020

\section{Keywords:}

Attenuated total reflection Fourier-transform infrared spectroscopy (ATR-FTIR)

Real-time polymerase chain reaction (RT-PCR)

Saliva biomarkers

Tumor mixus (TM)

Salivary gland tumor

\begin{abstract}
A B S T R A C T
The paper concentrates on the role of saliva in the early diagnosis of salivary gland tumor. Due to the still not fully understood etiology of head and neck cancer, the fundamental objective of this study is to find tumor markers of salivary gland tumor progression. This work demonstrates the feasibility of Attenuated Total Reflection Fourier Transform Infrared spectroscopy (ATR-FTIR) to track spectral variations between saliva samples derived from healthy volunteers and from salivary gland tumor (tumor mixus, TM) patients. Furthermore, a Real-Time Polymerase Chain Reaction (RT-PCR) has been used to detect a selected genes expression associated with neoplasm changes.

The obtained results imply that spectral signals attributed to the amide I/II (secondary structure of protein), carbohydrates and inorganic phosphates oscillations are the most sensitive to alterations associated with the salivary gland cancer progression. Several spectroscopic biomarkers have been indicated as potential predictors of salivary gland tumor development. Additionally, the RT-PCR results reveal the increased level of Bcl-2 factor in salivary gland tumor patients' samples which may be related to inhibition of apoptosis process and increasing uncontrolled cell proliferation. Such combination of physico-chemical methods is a unique approach towards better understanding the tumor's etiology and early diagnosis problem. Based on the promising findings presented in this article, it could be concluded that saliva fluid has a great potential to be used as a first-line diagnostic tool in patients with suspicion of salivary gland tumor.
\end{abstract}

(c) 2020 Elsevier B.V. All rights reserved.

\section{Introduction}

Neoplasm is still the most common disease of civilization and represents one of the main causes of the morbidity and mortality worldwide. The effective treatment of neoplasm is associated with the proper choice of therapy, but it also depends on the early diagnosis. One of the most difficult type of tumor, especially due to the problematic location is a head and neck neoplasm [1].

The biomolecular achievements of the neoplastic process have helped in understanding of this tumor mechanism and an early detection greatly increases the chances for successful treatment [2]. A searching for new biomarkers can contribute to early detection of this disease [3]. In our study, we put a special attention on the salivary glands disorders. Salivary gland tumors comprise approximately 3 to $10 \%$ of all head and neck neoplasms and the global incidence is estimated on 0.4 to 13.5 per 100,000 persons annually [4]. Most of these neoplasms are mixed tumors and are localized in parotid glands $[5,6]$.

\footnotetext{
* Corresponding author.

E-mail address: ewa.pieta@ifj.edu.pl (E. Pięta).
}

Multiple authors [7-9] emphasize a significant diagnostic role of ultrasonographic investigations (USG) in patients with parotid tumors. The procedure allows for precise evaluation of lesions in the parotid superficial lobe while assessment of the deep lobe appears much more difficult. The USG allows for tumor localization within the gland, evaluation of it size and preliminary histology. The literature often assumes such procedure as a diagnostic standard [10].

Histological evaluation of a tumor is possible due to the fine needle aspiration (FNA) biopsy, which is commonly carried out on every patient with a parotid tumor for the further diagnosis. The risk of the tumor spread in tissues passed through by the needle is low, however FNA is associated with the risk of multiple false negative results [2]. For instance, in the case of small tumors some of the morphological changes can be diagnosis as benign lesions, where there is a malignant lesion or alterations may be completely invisible [11].

Moreover, FNA can lead to some other defects. Firstly, it provides a lot of stress and patients discomfort. Secondly, there are often incompatibilities between pre- and postoperative histological examinations, which depend only on the pathologist's experience [12]. Finally, biopsy involves a high-cost and time-consuming procedure, therefore we 
postulate to find a better solution for analysis, which can be used for non-invasive monitoring of tumors development. A good direction seems to be using biochemical substances contained in body fluids such as saliva. The early diagnosis is the basis for effective treatment of head and neck tumor and what is more, a proper cure may facilitate the patient's return to social activity and reduce the chance of the recurrence. One of the non-invasive and rapid method related with salivary gland disorders is a detection of salivary contents. In the recent several years, there has been a growing interest in application of saliva to biomedical research [13]. This body fluid plays an important role as a factor responses for maintaining homeostasis in the oral cavity. Except digestive and protective functions, the salivary fluid contains a lot of significant factors which may help to predict many of diseases progression. The main components of saliva is a water, but otherwise, it contains also numerous of proteins, lipids, carbohydrates, ions and vitamins [14]. The most useful biomarkers contained in saliva for biomedical diagnosis are mucins, enzymes, immunoglobulins, hormones and other factors such as EGF - an epidermal growth factor which plays an important role in the process of carcinogenesis $[15,16]$.

It seems interesting to measure a number of proteins, lipids or enzymes contained in salivary fluid as biomarkers of tumors. Moreover, the genetic material such as DNA can be detected in saliva as well [17]. Therefore, the analysis of proteins structure and gene expression may be a good way to predict the early neoplasm changes on the proteomic and genetic level. Due to the rich content, saliva is functionally equivalent to blood, but what is important, it is a non-infectious fluid in contrast to blood. Moreover, saliva has even more advantages such as long durability, high bioavailability and cost-effectiveness [18]. The abovementioned biomarkers contained in saliva may provide an important information about many diseases including tumors, thus saliva seems to be very useful in reflecting the physiological state of the body. Collecting of saliva is a non-invasive technique with easy storage, simple procedures of preparation, and most importantly, comfortable for the patients.

The etiology of head and neck tumors remains still not fully understood. Thus, the main target of this research was to find tumor markers of salivary gland tumor based on the analysis of conformational changes of proteins, lipids and DNA by FTIR spectroscopy, which has a number of medical applications [19-30]. FTIR spectroscopy has the potential to provide information about changes occurring during cancer development but also brings new challenges connected with implementation of this method in the clinical environment [21]. Nonetheless, application and development of this method for medical purposes may be crucial for prevention and treatment processes.

In this work, we discuss spectral alterations between saliva samples derived from healthy volunteers and from salivary gland tumor patients. Additionally, we used a real - time polymerase chain reaction (RT-PCR), a biomolecular technique to detect a selected genes expression associated with neoplasm changes. Tumor cells may be dependent on $\mathrm{Bcl}-2$ gene, which is an antiapoptotic factor, in order to survive. In response to stress signals, malignant cells may express pro-apoptotic activators, but usually cancer cells overexpress Bcl-2, which can decreases this pro-apoptotic response. Therefore, the measurement of this important factor seems to be important in the analysis of early diagnosis of neoplastic changes.

The combination of proposed physico-chemical methods allowed to get an interdisciplinary view on the tumor's etiology and early diagnosis problem.

\section{Material and methods}

\subsection{Saliva samples preparation}

The investigated group included five healthy volunteers (control group) and five patients diagnosed with salivary gland tumor (tumor mixus, TM). All of salivary samples were freshly obtained in the morning. The patients and volunteers were required not to consume any meals or drinks $8 \mathrm{~h}$ prior to saliva collection and rinse their mouth only by water. Then, about $15 \mathrm{ml}$ of whole saliva and internal cheeks swab from the oral cavity were collected into the sterile tubes. Subsequently, all materials were frozen at $-20^{\circ} \mathrm{C}$ until analysis time. Shortly before measurement, salivary samples were thawed and centrifuged to obtain the sediment for Real-time PCR analysis or liquid supernatant for spectroscopic measurement. In ATR-FTIR method, the salivary samples were additionally dried on optical slides.

\subsection{ATR-FTIR measurements}

ATR-FTIR spectra of saliva samples were recorded using the Nicolet iS5 spectrometer with a iD5 ZnSe ATR accessory (Thermo Scientific). The deuterated triglycine sulfate (DTGS) detector was applied to register spectral signal in the range from $4000 \mathrm{~cm}^{-1}$ to $700 \mathrm{~cm}^{-1}$. An appropriate measurement procedure was established before a series of measurement. Namely, $20 \mu \mathrm{l}$ of fresh saliva fluid was deposited onto the ATR crystal and allowed to dry at room temperature. The number of scans was 64 , and the spectral resolution was $4 \mathrm{~cm}^{-1}$. The spectra were recorded three times for each freshly prepared sample and were averaged to yield a single spectrum per patient. The spectra were normalized to the amide I band $\left(\sim 1647 \mathrm{~cm}^{-1}\right)$. No smoothing procedure was used to improve visual quality of any spectra presented.

\subsubsection{Data reduction and treatment schemes}

Graphical interpretation, data reduction of the recorded spectra were performed using OMNIC 9.0 software product. The curve-fitting analysis (a Gaussian band shape) and the second derivatives (Savitzky-Golay, 7 points) were carried out using the OMNIC 9.0 software.

\subsection{Real-time PCR study}

The level of Bcl-2 gene expression, an antiapoptotic factor which is strongly related with proliferation process was measured in saliva samples of patients with salivary gland tumor (tumor mixus) and control volunteers. The analyses were performed in stages as follow.

\subsubsection{RNA isolation}

The total RNA was extracted from fresh salivary samples in spin columns with lysis buffers by RNeasy Mini Kit (Qiagen, Netherlands) ac-

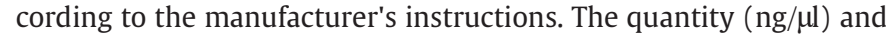
quality of RNA (1.8-2.0) was determined by Spark 10 M spectrophotometer (Tecan, Switzerland) at 260 and 280 wavelength.

\subsubsection{Reverse transcription}

Next step was applied with Precision nanoScript kit (PrimerDesign, UK) in $0.2 \mathrm{ml}$ PCR tubes with 50 ng of RNA template and other reagents. Each sample was submitted to the annealing step in $65^{\circ} \mathrm{C}$ for $5 \mathrm{~min}$ in thermocycler (Bio-rad, USA) and then incubated $20 \mathrm{~min}$ in $42{ }^{\circ} \mathrm{C}$ and $10 \mathrm{~min}$ in $75^{\circ} \mathrm{C}$ for extension stage.

\subsubsection{Real-time $P C R$}

The final step was performed by Precision PLUS qPCR protocol (PrimerDesign, UK) using Master MIX SYBR Green (10 $\mu \mathrm{l})$, forward and reverse primers (per $0.25 \mu \mathrm{M}$ ), cDNA template (25 ng) and RNAse/DNAse free water (up to $20 \mu \mathrm{l}$ ). The temperature-time conditions of the reaction were determined as follows: $2 \mathrm{~min}$ in $95^{\circ} \mathrm{C}$ for enzyme activation, then denaturation in $95^{\circ} \mathrm{C}$ for $10 \mathrm{~s}$ and $1 \mathrm{~min}$ in $60^{\circ} \mathrm{C}$ for primers annealing.

\subsubsection{Analysis}

The relative expression of Bcl-2 gene was quantified using the comparative threshold cycle $\left(\Delta \Delta C_{T}\right)$ after normalizing to reference gene 
(GAPDH) by $2^{-\Delta \Delta C T}$ Livak's method. All experiments were performed in triplicates.

\section{Results and discussion}

\subsection{ATR-FTIR study}

Fig. 1 shows the ATR-FTIR spectra of saliva sample: (a) control (spectrum averaged from five healthy volunteers samples), and salivary gland tumor (tumor mixus, TM) patients: (b) M70TM1, (c) K39TM2, (d) K45TM3, (e) K48TM4, and (f) M40TM5 (M - man, W - woman). As is evident from the spectra, there are significant changes in bands positions and relative intensities, which may be associated with the development of a tumor. Nevertheless, there are a lot of overlapping bands in the fingerprint region, especially in the $900-1200 \mathrm{~cm}^{-1}$ and amide I and II spectral regions. Therefore, the curve-fitting analysis of these areas is necessary for more conclusive band assignments (please see Fig. 2a - d). Furthermore, for a better comparison of the spectral alterations between control group and patients diagnosed with cancer, the average spectra were imposed on each other (Fig. 2e). Table 1 lists the most characteristic ATR-FTIR bands together with suggested band assignments for averaged spectra of control (healthy volunteers) and salivary gland tumor patients. The vibrational analysis was based on the latest literature reports and databases on the application of FTIR spectroscopy in biological studies with particular emphasis on saliva analysis [31-48].

The high frequency range is dominated by bands assigned to protein and lipid constituents [31,32]. Briefly, peaks observed at the spectral interval between 3600 and $3000 \mathrm{~cm}^{-1}$ originate from $\mathrm{C}-\mathrm{H}, \mathrm{O}-\mathrm{H}$ and $\mathrm{N}-\mathrm{H}$ stretching modes of proteins, while strong band at $3286 \mathrm{~cm}^{-1}$ is attributed to amide $\mathrm{A} \mathrm{N}-\mathrm{H}$ stretching [33]. Another spectral feature appearing at $\sim 3073 \mathrm{~cm}^{-1}$ is due to amide $\mathrm{B} v(\mathrm{NH}) / v(\mathrm{CH})$ vibrations in proteins $(\alpha-$ amylase, albumin, cystains, mucins, proline-rich proteins, slgA) [33-35]. On the other hand, the spectral region $3000-2800 \mathrm{~cm}^{-1}$ is rich in bands ascribed to symmetric and asymmetric $\mathrm{CH}_{2}$ and $\mathrm{CH}_{3}$ stretching oscillations of lipids [33,36-38].

It has to be noted that the most evident alterations occur in the region between $\sim 900$ and $1300 \mathrm{~cm}^{-1}$. Nonetheless, some of bands in the fingerprint region may overlap. This spectral interval is regarded as a highly diagnostic region in studying various cancer types [33,35-44,49-57]. Band arising at $\sim 1078 \mathrm{~cm}^{-1}$ is related to the asymmetric and symmetric $\mathrm{PO}_{2}^{-}$stretching from symmetric $\mathrm{PO}_{2}^{-}$stretching from inorganic phosphates [58] and phosphate group of phospholipids [48]. It was proved that this spectral feature is associated with the role of phosphates during diseases [50]. Thus, remarkable increase in $\sim 1074 \mathrm{~cm}^{-1}$ band intensity in the spectrum of TM in relation to the spectrum of control group may be correlated with the disease development (Fig. 2e) [50,54,55]. This band is especially pronounced in the case of TM spectra. Moreover, a noticeable displacement of the band position (from $1078 \mathrm{~cm}^{-1}$ in control group to $1074 \mathrm{~cm}^{-1}$ for patients with salivary gland tumor) confirms the participation of phosphates upon the investigated disease development [50]. Apart from the aforementioned bands, vibration come from phosphate group is manifested in the spectra at $~ 1159,1239$ and 985 , and $936 \mathrm{~cm}^{-1}$ [58]. Heise and Marbarch [48] have thoroughly studied human oral mucosa tissue from several patients under changing blood glucose concentrations by ATR-FTIR spectroscopy. Interestingly, the obtained FTIR spectra of saliva dry film and

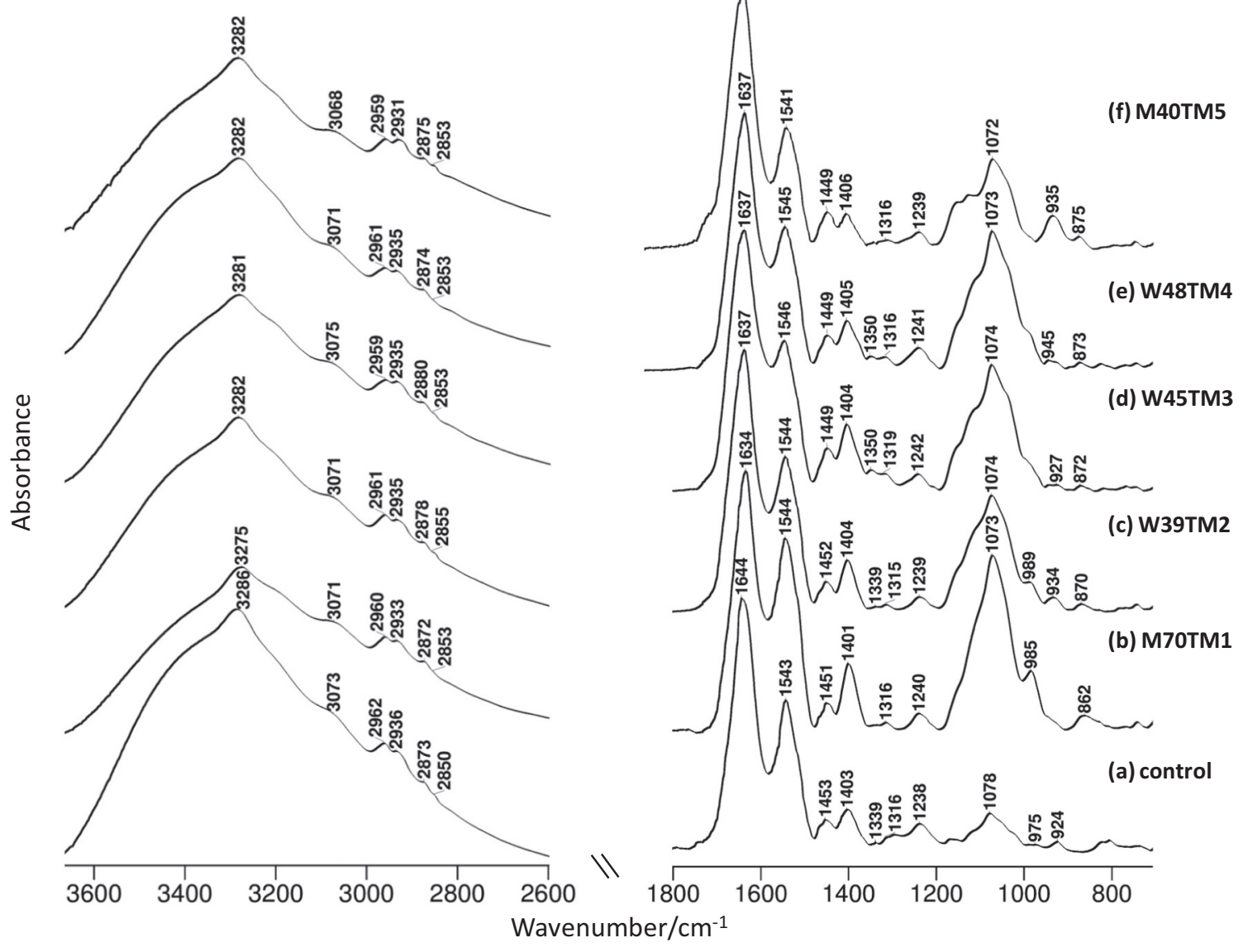

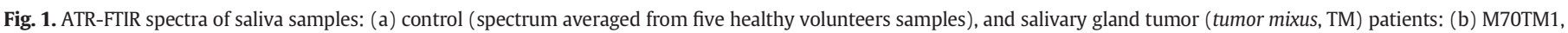
(c) K39TM2, (d) K45TM3, (e) K48TM4, and (f) M40TM5. M - man, W - woman. 


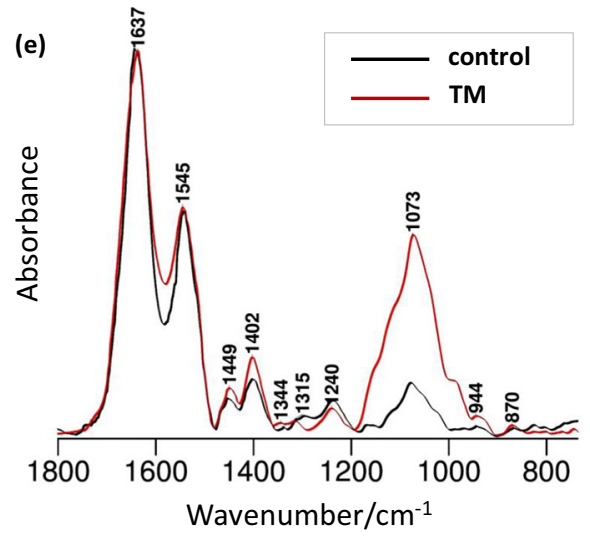

(a) $900-1200 \mathrm{~cm}^{-1}$ : control

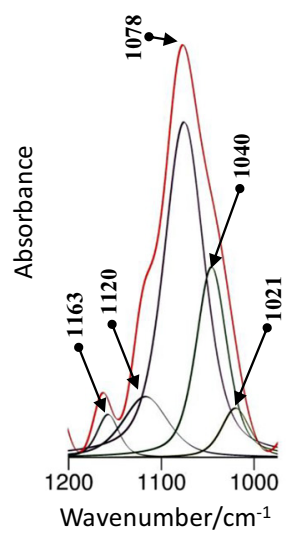

(b) $900-1200 \mathrm{~cm}^{-1}: \mathrm{TM}$

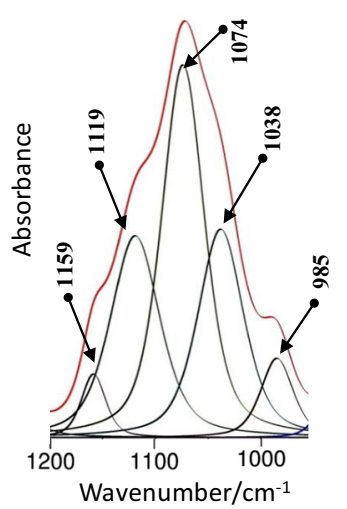

(c) amide I and II - control

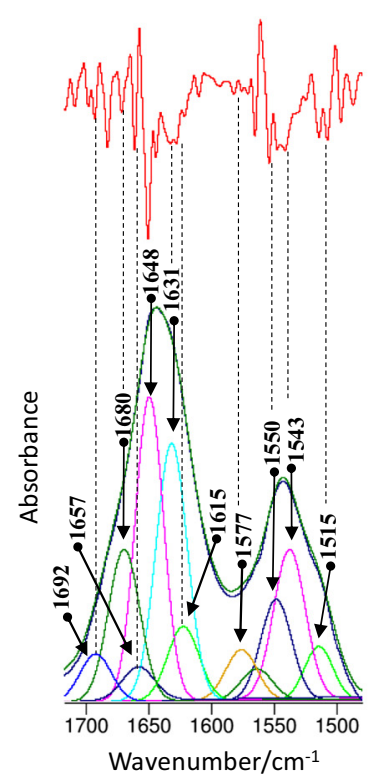

(d) amide I and II - TM

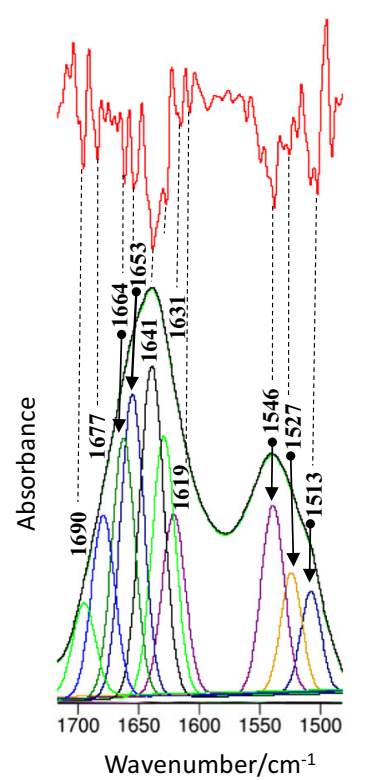

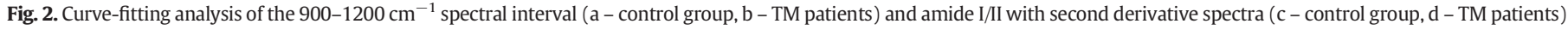

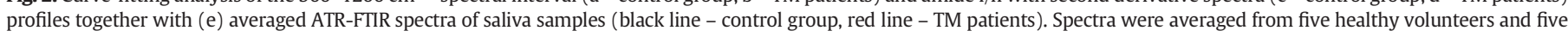
salivary gland tumor patients spectra, respectively.

saliva difference spectrum received after subtraction of a scaled phosphate buffer spectrum revealed significant contribution of inorganic phosphate features on the spectral patterns [48].

Furthermore, peaks observed within the 1000 to $1200 \mathrm{~cm}^{-1}$ interval may also be attributed to the $\mathrm{C}-\mathrm{O}$ stretching vibrations from carbohydrates. Consequently, bands at 1021,1040 and $1078 \mathrm{~cm}^{-1}$ originate from sugar moieties $[41,44,48]$. Nevertheless, due to the fact that most of the salivary proteins are glycosylated, these peaks can be attributed to glycosylated $\alpha$-amylase, mucins or other sugar residues vibrations [44,48,59-61]. It is also worth pointing out that $1119 \mathrm{~cm}^{-1}$ spectral signal due to the $v(\mathrm{C}-\mathrm{O})$ and $v(\mathrm{C}-\mathrm{O}-\mathrm{C})$ of carbohydrates vibrations in TM spectrum exhibits significant enhancement in comparison to the non-cancerous spectrum [28,33]. The discussed oscillations are regarded as spectral biomarkers to distinguish between normal from cancer states [62], while the $1119 \mathrm{~cm}^{-1}$ peak is considered as a spectroscopic marker of salivary gland tumor [53]. Most of these motions reveal noticeable strengthened upon disease development (Figs. 1 and 2e). These results are consistent with other studies which have shown that FTIR spectroscopy can be successfully employed to distinguish normal from cancer states, especially considering the spectral interval between 800 and $1300 \mathrm{~cm}^{-1}[53,57,62,63]$.

There are also significant alterations in secondary structure of proteins (Fig. 1) between ATR-FTIR spectrum of control and salivary gland tumor patients. It must be noted that the $\alpha$-helix maximum peak frequency decreased for the TM spectrum $\left(1634-1640 \mathrm{~cm}^{-1}\right.$; Fig. 1b-f) in comparison to the spectrum of control group $\left(1644 \mathrm{~cm}^{-1}\right.$; Fig. 1a). Simultaneously, the $\beta$-sheet maximum band frequency (1543 $\mathrm{cm}^{-1}$; Fig. 1a) increased for the salivary gland tumor patients (Fig. 1b-d), except in the case of M40TM5 (Fig. 1f) [33-39,44]. It is consistent with literature and may results from variations in the extent of intermolecular hydrogen bond in $\alpha$-helical and $\beta$-sheet structures [64]. Furthermore, the most intense band appearing at $1648 \mathrm{~cm}^{-1}$ attributed to $v(\mathrm{C}=0),(\mathrm{CN})$ and $\delta(\mathrm{NH})$ vibrations from $\alpha$-helix upon deconvolution split into two additional bands at 1664 and $1641 \mathrm{~cm}^{-1}$ due to the disordered structure-solvated $\left[v_{s}(C=0)\right]$ and unordered structure $[v(C=0)]$, respectively (Fig. $2 c$ and $d$ ). Another observation concerns the content of $\alpha$-helical conformation, which decreased noticeably for TM patients (Fig. 2c and d; Table 1). This may be related to the formation of $\beta$-sheet structure [65]. It is also worth noting that the relative intensity of $1631 \mathrm{~cm}^{-1}$ band due to the $\beta$-sheet structure $[v(C=0) / v(C=C)]$ significantly decrease upon cancer development. Conversely, the composition of $1615 \mathrm{~cm}^{-1}$ spectral signal ascribed to the $\beta$-sheet formation $[v(C=C)]$ increased considerably for TM spectral data $[33-39,44]$. It has also be noted that peaks arising at $1403\left[v_{\mathrm{s}}\right.$ $\left.\left(\mathrm{COO}^{-}\right), \rho_{\mathrm{b}}\left(\mathrm{CH}_{3}\right)\right]$ and $1450 \mathrm{~cm}^{-1}\left[\rho_{\mathrm{b}}\left(\mathrm{CH}_{3}\right) / \delta\left(\mathrm{CH}_{2} / \mathrm{CH}_{3}\right)\right]$ exhibit higher intensity for the TM patients. Another prominent spectral features assigned to proteins can be observed at $1543\left[\rho_{\mathrm{b}}(\mathrm{NH}), v(\mathrm{CN})\right.$, amide II], 1515 [trosine ring, $\alpha$-amylase, albumin, cystains, mucins, prolinerich proteins, sIgA] and $1315 \mathrm{~cm}^{-1}\left[v(\mathrm{CN}), \rho_{\mathrm{b}}(\mathrm{NH})\right.$, amide III ( $\alpha$-amylase, albumin, cystains, mucins, proline-rich proteins, sIgA)]. Additional FTIR signal, which is absent in the case of the control group spectrum, appears at $1527 \mathrm{~cm}^{-1}\left[\rho_{\mathrm{b}}(\mathrm{NH}), v(\mathrm{C}=\mathrm{N}), v(\mathrm{C}=\mathrm{C})\right.$, amide II]. The above observations clearly indicates that the secondary structure of proteins in healthy volunteers samples differ significantly from that in TM patients samples.

\subsection{Real-time PCR study}

To determinate the anti-apoptotic gene (Bcl-2) expression, a total RNA extraction and then cDNA strand from all of salivary samples 
Table 1

Wavenumber and suggested band assignments for averaged ATR-FTIR spectra of control (healthy volunteers) and salivary gland tumor (tumor mixus, TM) patients. ${ }^{\mathrm{a}}$

\begin{tabular}{|c|c|c|c|c|}
\hline \multicolumn{2}{|c|}{ FTIR bands $\left[\mathrm{cm}^{-1}\right]$} & \multirow[t]{2}{*}{ Band assignment } & \multirow[t]{2}{*}{ Component identification } & \multirow[t]{2}{*}{ Reference number } \\
\hline Control & $\mathrm{TM}$ & & & \\
\hline 3286 & 3282 & $v_{\mathrm{as}}(\mathrm{NH})$ & Amide A & [31-38] \\
\hline 3073 & 3074 & $v(\mathrm{NH}) / v(\mathrm{CH})$ & Amide B/ring ( $\alpha$-amylase, albumin, cystains, mucins, proline-rich proteins, sIgA) & [31-38] \\
\hline 2962 & 2961 & $v_{\mathrm{as}}\left(\mathrm{CH}_{3}\right)$ & Lipids, protein side chains & [31-38] \\
\hline 2936 & 2935 & $v_{\mathrm{as}}\left(\mathrm{CH}_{2}\right)$ & Lipids & [31-38] \\
\hline 2873 & 2874 & $v_{\mathrm{s}}\left(\mathrm{CH}_{3}\right)$ & Lipids, protein side chains & [31-38] \\
\hline 2850 & 2851 & $\nu_{\mathrm{s}}\left(\mathrm{CH}_{2}\right)$ & Lipids (cholesterol and mono/diglycerides of fatty acids) & [31-38] \\
\hline 1692 & 1690 & $v(\mathrm{C}=\mathrm{O}), v(\mathrm{CN}), \rho_{\mathrm{b}}(\mathrm{NH})$ & Amide I: anti-parallel $\beta$-sheet & {$[33-39,44]$} \\
\hline \multirow[t]{2}{*}{1680} & 1677 & $v(C=0)$ & Amide I: unordered random coils and turns & {$[33-39,44]$} \\
\hline & 1664 & $v_{\mathrm{s}}(\mathrm{C}=0)$ & Amide I: disordered structure-solvated & {$[33-39,44]$} \\
\hline \multirow[t]{2}{*}{1648} & 1653 & $\nu(\mathrm{C}=0), \delta(\mathrm{CN}), \delta(\mathrm{NH})$ & Amide I: $\alpha$-helix & {$[33-39,44]$} \\
\hline & 1641 & $v(\mathrm{C}=0)$ & Amide I: unordered structure & {$[33-39,44]$} \\
\hline 1631 & 1631 & $v(\mathrm{C}=0) / v(\mathrm{C}=\mathrm{C})$ & Amide I: $\beta$-sheet structure & {$[33-39,44]$} \\
\hline 1615 & 1619 & $v(\mathrm{C}=\mathrm{C})$ & Amide I: $\beta$-sheet structure & {$[33-39,44]$} \\
\hline \multirow[t]{2}{*}{1543} & 1546 & $\rho_{\mathrm{b}}(\mathrm{NH}), v(\mathrm{CN})$ & Amide II & {$[33-39,44]$} \\
\hline & 1527 & $\rho_{\mathrm{b}}(\mathrm{NH}), v(\mathrm{C}=\mathrm{N}), v(\mathrm{C}=\mathrm{C})$ & Amide II & {$[33-39,44]$} \\
\hline 1515 & 1513 & tyrosine ring & Proteins ( $\alpha$-amylase, albumin, cystains, mucins, proline-rich proteins, sIgA) & {$[33-39,44]$} \\
\hline 1451 & 1450 & $\rho_{\mathrm{b}}\left(\mathrm{CH}_{3}\right) / \delta\left(\mathrm{CH}_{2} / \mathrm{CH}_{3}\right)$ & Proteins/lipids & {$[33,36,38]$} \\
\hline \multirow[t]{2}{*}{1407} & 1403 & $v_{\mathrm{s}}\left(\mathrm{COO}^{-}\right)$ & Fatty acids & {$[33,35,38,40]$} \\
\hline & & $\rho_{\mathrm{b}}\left(\mathrm{CH}_{3}\right)$ & Proteins & {$[33,36,40]$} \\
\hline 1341 & 1343 & $\rho_{\mathrm{w}}\left(\mathrm{CH}_{2}\right)$ & Phospholipids, fatty acid, triglyceride, amino acid side chains & [33] \\
\hline 1315 & 1315 & $\nu(\mathrm{CN}), \rho_{\mathrm{b}}(\mathrm{NH})$ & Amide III ( $\alpha$-amylase, albumin, cystains, mucins, proline-rich proteins, sIgA) & {$[33,35,38,40]$} \\
\hline \multirow[t]{2}{*}{1239} & 1243 & $v_{\mathrm{as}}\left(\mathrm{PO}_{2}^{-}\right)$ & Phosphate group of phospholipids & {$[33,36,38,48]$} \\
\hline & & $\nu_{\mathrm{as}}\left(\mathrm{PO}_{2}^{-}\right)$ & Inorganic phosphates & {$[28,33,36]$} \\
\hline \multirow[t]{2}{*}{1163} & 1159 & $v_{\text {as }}\left(\mathrm{PO}_{2}^{-}\right)$ & Inorganic phosphates & [58] \\
\hline & & $v(\mathrm{CO}), v(\mathrm{C}-\mathrm{O}-\mathrm{H})$ & Serine, threonine, tyrosine of proteins & {$[33,35,40]$} \\
\hline 1120 & 1119 & $v(\mathrm{C}-\mathrm{O}), v(\mathrm{C}-\mathrm{O}-\mathrm{C})$ & Carbohydrates & {$[28,33]$} \\
\hline \multirow[t]{3}{*}{1078} & 1074 & $v_{\mathrm{s}}\left(\mathrm{PO}_{2}^{-}\right)$ & Inorganic phosphates & {$[33,48,58]$} \\
\hline & & $v_{\mathrm{s}}\left(\mathrm{PO}_{2}^{-}\right), v_{\mathrm{as}}\left(\mathrm{PO}_{2}^{-}\right)$ & Phosphate group of phospholipids & {$[33,35-44,48]$} \\
\hline & & $v(\mathrm{CO}), \rho_{\mathrm{b}}(\mathrm{C}-\mathrm{O}-\mathrm{H})$ & Glycosylated $\alpha$-amylase, mucins or other sugar residues & {$[41,44,48]$} \\
\hline 1040 & 1038 & $\nu(\mathrm{CO}), \rho_{\mathrm{b}}(\mathrm{C}-\mathrm{O}-\mathrm{H})$ & Glycosylated $\alpha$-amylase, mucins or other sugar residues & {$[41,44,48]$} \\
\hline 1021 & & $v(\mathrm{CO}), \delta(\mathrm{C}-\mathrm{O}-\mathrm{H})$ & Glycosylated $\alpha$-amylase, mucins or other sugar residues & {$[41,44,48]$} \\
\hline 975 & 985 & $v\left(\mathrm{PO}_{2}^{-}\right)$ & Inorganic phosphates & {$[58]$} \\
\hline \multirow[t]{3}{*}{924} & 936 & $v\left(\mathrm{PO}_{2}^{-}\right)$ & Inorganic phosphates & [58] \\
\hline & & $\delta(\mathrm{COH}), \delta(\mathrm{COC})$ & Carbohydrates & {$[33,40]$} \\
\hline & & $\nu_{\mathrm{as}}\left(\mathrm{CH}_{3}-\mathrm{N}\right)$ & Phospholipids & {$[33,40]$} \\
\hline
\end{tabular}

a Abbreviations: $v$, stretching; $\delta$, deformation; $\rho_{\mathrm{b}}$, bending; as, asymmetric; $s$, symmetric.

were used as a template for Real-time PCR detection. Our research, based on comparative $\Delta \Delta C_{t}$ analysis, indicates increased level of Bcl-2 expression in saliva of patients with salivary gland tumor (tumor mixus). Fig. 3 shows several times higher relative expression (RQ) of Bcl-2 factor in all of 5 patients samples in compare to the averaged results from 5 healthy volunteers samples (control). The most significant changes were noticed in M70TM1 and K39TM2 cases (6-folds higher expression than control samples), where in all of other samples (K45TM3, K48TM4, and M40TM5) the Bcl-2 gene level was increased approximately 3 times. The presented results illustrate changes

\section{Bcl-2 expression}

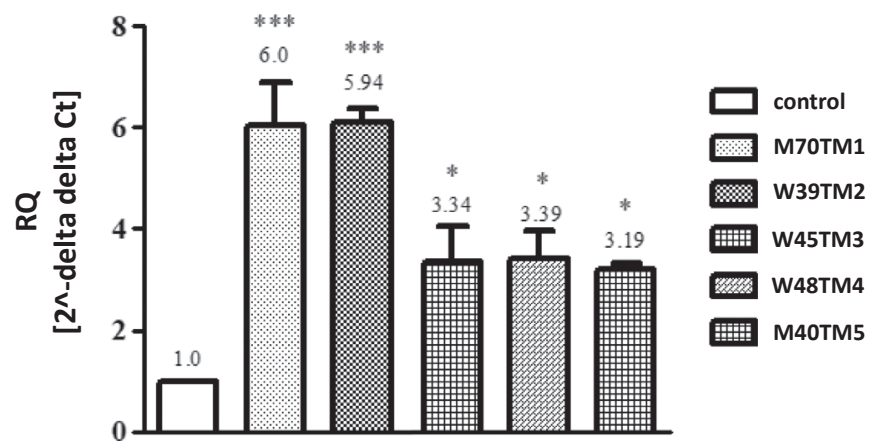

Fig. 3. Relative expression of antiapoptotic factor Bcl-2 in saliva of patients with salivary gland tumor vs control volunteers. One-way ANOVA analysis followed by the NewmanKeuls post hoc test. Statistical significance was assessed using GraphPad Prism 5.0 software and $\mathrm{P}$ value $<0.005$ was considered statistically significant. characteristic for tumors development by inhibiting of programmed cells death (apoptosis).

\section{Conclusions}

From the research that has been carried out it possible to conclude that saliva can be regarded as a first-line diagnostic tool in patients with suspicion of salivary gland tumor. ATR-FTIR spectroscopy can be successfully applied for distinguishing between control group and salivary gland tumor patients. It has been demonstrated that there are significant changes in secondary structure of proteins upon cancer development. We highlighted spectroscopic biomarkers associated with salivary gland tumor development, in particular bands attributed to proteins, carbohydrates and inorganic phosphates.

Moreover, our biomolecular studies indicated the differences in antiapoptotic gene expression between patients with salivary gland tumor (tumor mixus) and control volunteers. Increased level of Bcl-2 factor in patients' samples may be related to inhibition of apoptosis process and increasing uncontrolled cell proliferation, which is strongly related to neoplastic development. Therefore, we confirmed that salivary fluid can be very useful and significant tool for early diagnosis based on biomarkers contained in saliva. To summarize, our research may be a first step for searching modern solutions for early detection of oral tumors based on salivary samples.

\section{CRediT authorship contribution statement}

Czesława Paluszkiewicz: Conceptualization, Methodology, Supervision. Ewa Pięta: Investigation, Writing - original draft, Writing - review \& editing, Visualization, Formal analysis. Monika Woźniak: 
Investigation, Visualization, Writing - original draft. Natalia Piergies: Investigation, Visualization. Anna Koniewska: Resources. Wojciech Ścierski: Resources, Funding acquisition, Investigation. Maciej Misiołek: Resources, Funding acquisition. Wojciech M. Kwiatek: Supervision.

\section{Declaration of competing interest}

The authors have no conflict of interests to declare.

\section{Acknowledgments}

This study was partially supported by the statuary research of Medical University of Silesia in Katowice, Poland, project No. KNW-1-159/N/ $8 / K / 2018$. The study was performed using equipment purchased in the frame of the project co-funded by the Małopolska Regional Operational Program Measure 5.1 Krakow Metropolitan Area as an important hub of the European Research Area for 2007-2013, project No. MRPO.05.01.00-12-013/15. The authors acknowledge Ms. Jolanta Adamczyk for her invaluable assistance with the measurements.

\section{References}

[1] M. Guzzo, L.D. Locati, F.J. Prott, G. Gatta, M. McGurk, L. Licitra, Major and minor salivary gland tumors, Crit. Rev. Oncol. Hematol. 74 (2010) 134-148.

[2] K. Awan, S. Patil, S. Islam, M. Jafer, Early detection of oral cancer - guidelines for dental practitioners, J. Int. Oral Health 8 (2016) 399-403.

[3] K. Dahiya, R. Dhankhar, Updated overview of current biomarkers in head and neck carcinoma, World J. Methodol. 6 (1) (2016) 77-86.

[4] I. Schwentner, P. Obrist, W. Thumfart, G. Sprinzl, Distant metastasis of parotid gland tumors, Acta Otolaryngol. 126 (2006) 340-345.

[5] N. Sadeghi, S. Al-Dhahri, J.J. Manoukian, Transnasal endoscopic medial maxillectomy for inverting papilloma, Laryngoscope 113 (2003) 749-753.

[6] W.S. Kim, D.W. Hyun, C.H. Kim, J.H. Yoon, Treatment outcomes of sinonasal inverted papillomas according to surgical approaches, Acta Otolaryngol. 130 (2010) 493-497.

[7] H. Alphs, D. Eisele, W. Westra, The role of fine needle aspiration in the evaluation of parotid masses, Curr Opin Otolaryngol Head Neck Surg (2) (2006) 62-66.

[8] E. Matsuda, T. Fukuhara, R. Donishi, K. Kawamoto, Y. Hirooka, H. Takeuchi, Usefulness of a novel ultrasonographic classification based on anechoic area patterns for differentiating Warthin Tumors from pleomorphic adenomas of the parotid gland, Yonago Acta Med 60 (2018) 220-226.

[9] L. Luczewski, P. Golusinski, J. Pazdrowski, P. Pienkowski, M. Kordylewska, W. Golusinski, The ultrasound examination in assessment of parotid gland tumours: the novel graphic diagram, Eur. Arch. Otorhinolaryngol. 270 (2013) 2129-2133.

[10] M. Sahin, I. Tatar, A. Kurt, et al., Importance of sonoelastography in assessing nonthyroid neck masses, Turk. Arch. Otorhinolaryngol. 55 (2017) 10-16.

[11] K. Gajjar, A. Ahmadzai, G. Valasoulis, J. Trevisan, C. Founta, M. Nasioutziki, A. Loufopoulos, M. Kyrgiou, S. Stasinou, P. Karakitsos, E. Paraskevaidis, B. Da GamaRose, P. Martin-Hirsch, F. Martin, Histology verification demonstrates that biospectroscopy analysis of cervical cytology identifies underlying disease more accurately than conventional screening: removing the confounder of discordance, PLoS One 9 (2014), e82416-e82416.

[12] M. Jandu, K. Webster, The role of operator experience in the fine needle aspiration cytology of head and neck masses, Int. J. Oral Maxillofac. Surg. 28 (1999) 441-444.

[13] C. Miller, J. Foley, A. Bailey, C. Campell, R. Humphries, N. Christodoulides, P. Floriano, G. Simmons, B. Bhagwandin, J. Jacobson, S. Redding, J. Ebersole, J. McDevitt, Current developments in salivary diagnostics, Biomark. Med 4 (1) (2010) 171-189.

[14] T. Pfaffe, J. Cooper-White, P. Beyerlein, K. Kostner, C. Punyadeera, Diagnostic potential of saliva: current state and future applications, Clin. Chem. 57 (5) (2011) 675-687.

[15] K.E. Kaczor-Urbanowicz, F. Wei, S.L. Rao, J. Kim, H. Shin, J. Cheng, M. Tu, D.T.W. Wong, Y. Kim, Clinical validity of saliva and novel technology for cancer detection, BBA - Rev. Cancer 1872 (2019) 49-59.

[16] X. Wang, K.E. Kaczor-Urbanowicz, D.T.W. Wong, Salivary biomarkers in cancer detection, Med. Oncol. 34 (2017) 1-12.

[17] R. Pink, J. Simek, J. Vondrakova, E. Faber, P. Michl, J. Pazdera, K. Indrak, Saliva as a diagnostic medium, Biomed. Pap. Med. 153 (2) (2009) 103-110.

[18] Y. Lee, D. Wong, Saliva: an emerging biofluid for early detection of diseases, Am. J. Dent. 22 (4) (2009) 241-248.

[19] L. Lovergne, G. Clemens, V. Untereiner, R.A. Lukaszweski, G.D. Sockalingum, M.J. Baker, Investigating optimum sample preparation for infrared spectroscopic serum diagnostics, Anal. Meth. 7 (2015) 7140-7149.

[20] J.M. Cameron, H.J. Butler, D.S. Palmer, M.J. Baker, Biofluid spectroscopic disease diagnostics: a review on the processes and spectral impact of drying, J. Biophotonics 11 (2018), e201700299.

[21] M.J. Baker, H.J. Byrne, J. Chalmers, P. Gardner, R. Goodacre, A. Henderson, S.G. Kazarian, F.L. Martin, J. Moger, N. Stone, J. Sule-Suso, Clinical applications of infrared and Raman spectroscopy: state of play and future challenges, Analyst 143 (2018) 1735-1757.

[22] J. Wang, M. Sowa, H.H. Mantsch, A. Bittner, H.M. Heise, Comparison of different infrared measurement techniques in the clinical analysis of biofluids, TRAC-Trend. Anal. Chem. 75 (1996) 286-296.

[23] J. Ollesch, S.L. Drees, H.M. Heise, T. Behrens, T. Bruning, K. Gerwert, FTIR spectroscopy of biofluids revisited: an automated approach to spectral biomarker identification, Analyst 138 (2013) 4092-4102.

[24] A.L. Mitchell, K.B. Gajjar, G. Theophilou, F.L. Martin, P.L. Martin-Hirsch, Vibrational spectroscopy of biofluids for disease screening or diagnosis: translation from the laboratory to a clinical setting, J. Biophotonics 7 (2014) 153-165.

[25] C. Hughes, M. Brown, G. Clemens, A. Henderson, G. Monjardez, N.W. Clarke, P. Gardner, Assessing the challenges of Fourier transform infrared spectroscopic analysis of blood serum, J. Biophotonics 7 (2014) 180-188.

[26] F.L. Martin, J.G. Kelly, V. Llabjani, P.L. Martin-Hirsch, I.I. Patel, J. Trevisan, N.J. Fullwood, M.J. Walsh, Distinguishing cell types or populations based on the computational analysis of their infrared spectra, Nat. Protoc. 5 (2010) 1748-1760.

[27] M.J. Baker, J. Trevisan, P. Bassan, R. Bhargava, H.J. Butler, K.M. Dorling, P.R. Fielden, S.W. Fogarty, N.J. Fullwood, K.A. Heys, C. Hughes, P. Lasch, P.L. Martin-Hirsch, B. Obinaju, G.D. Sockalingum, J. Sulé-Suso, R.J. Strong, M.J. Walsh, B.R. Wood, P. Gardner, F.L. Martin, Using Fourier transform IR spectroscopy to analyze biological materials, Nat. Protoc. 9 (2014) 1771-1791.

[28] M.J. Baker, S.R. Hussain, L. Lovergne, V. Untereiner, C. Hughes, R.A. Lukaszewski, G. Thiefin, G.D. Sockalingum, Developing and understanding biofluid vibrational spectroscopy: a critical review, Chem. Soc. Rev. 45 (2016) 1803-1818.

[29] F. Bonnier, H. Blasco, C. Wasselet, G. Brachet, R. Respaud, L.F.C.S. Carvalho, D. Bertrand, M.J. Baker, H.J. Byrne, I. Chourpa, Ultra-filtration of human serum for improved quantitative analysis of low molecular weight biomarkers using ATR-IR spectroscopy, Analyst 142 (2017) 1285-1298.

[30] H.J. Butler, B.R. Smith, R. Fritzsch, P. Radhakrishnan, D.S. Palmer, M.J. Baker, Optimised spectral pre-processing for discrimination of biofluids via ATR-FTIR spectroscopy, Analyst 143 (2018) 6121-6134.

[31] C. Petibois, G. Cazorla, A. Cassaigne, A. Perromat, G. Deleris, Plasma protein contents determined by Fourier-transform infrared spectrometry, Clinical Chem 47 (2001) 730-738.

[32] G. Deleris, C. Petibois, Application of FT-IR spectrometry to plasma contents analysis and monitoring, Vib. Spectrosc. 32 (2003) 129-136.

[33] Z. Movasaghi, S. Rehman, I. ur Rehman, Fourier transform infrared (FTIR) spectroscopy of biological tissues, Appl. Spectrosc. Rev. 43 (2008) 134-179.

[34] A. Barth, Infrared spectroscopy of proteins, Biochim. Biophys. Acta 1767 (2007) 1073-1101.

[35] S. Abbas, N.S. Ozek, S. Emri, D. Koksal, M. Severcan, F. Severcan, Diagnosis of malignant pleural mesothelioma from pleural fluid by Fourier transform-infrared spectroscopy coupled with chemometrics, J. Biomed. Opt. 23 (2018), 105003.

[36] G. Bellisola, C. Sorio, Infrared spectroscopy and microscopy in cancer research and diagnosis, Am. J. Cancer Res. 2 (2012) 1-21.

[37] R.R. Sultana, S.N. Zafarullah, N.H. Kirubamani, Saliva signature of normal pregnant women in each trimester as analyzed by FTIR spectroscopy, Indian J. Sci. Technol. 4 (2011) 481-486.

[38] P.C. Caetano Jr., J.F. Strixino, L. Raniero, Analysis of saliva by Fourier transform infrared spectroscopy for diagnosis of physiological stress in athletes, Res. Biomed. Eng. 31 (2015) 116-124.

[39] L.M. Rodrigues, T.D. Magrini Alva, H. da Silva Martinho, J.D. Almeida, Analysis of saliva composition in patients with burning mouth syndrome (BMS) by FTIR spectroscopy, Vib. Spectrosc. 100 (2019) 195-201.

[40] R.P.C.B. Rodrigues, E.M.G. Aguiar, L. Cardoso-Sousa, D.C. Caixeta, C.C.F.V. Guedes, W.L. Siqueira, Y.C. Paiva Maia, S.V. Cardoso, R.N. Sabino-Silva, Differential molecular signature of human saliva using ATR-FTIR spectroscopy for chronic kidney disease diagnosis, Braz. Dent. J. 30 (2019) 437-445.

[41] L.V. Bel'skaya, E.A. Sarf, N.A. Makarova, Use of Fourier transform IR spectroscopy for the study of saliva composition, J. Appl. Spectrosc. 85 (2018) 445-451.

[42] L.V. Bel'skaya, E.A. Sarf, I.A. Gundyrev, Study of the IR spectra of the saliva of cancer patients, composition, J. Appl. Spectrosc. 85 (2019) 1076-1084.

[43] B.H. Stuart, Biological applications, Infrared Spectroscopy: Fundamentals and Applications, John Wiley \& Sons, Ltd 2005, pp. 137-165 , (ISBN 9780470011140).

[44] C.M. Orphanou, The detection and discrimination of human body fluids, using ATR FT-IR spectroscopy, Forensic Sci. Int. 252 (2015) e10-e16.

[45] D. Naumann, H. Fabian, P. Lasch, FTIR spectroscopy of cells, tissues and body fluids, Adv. Biomed. Spectrosc. 2 (2009) 312-354.

[46] C.E. Christersson, L. Lindh, T. Arnebrant, Film-forming properties and viscosities of saliva substitutes and human whole saliva, Eur. J. Oral Sci. 108 (2000) 418-425.

[47] C. Petibois, K. Gionnet, M. Goncalves, A. Perromat, M. Moenner, G. Deleris, Analytical performances of FT-IR spectrometry and imaging for concentration measurements within biological fluids, cells, and tissues, Analyst 131 (2006) 640-647.

[48] H.M. Heise, R. Marbach, Human oral mucosa studies with varying blood glucose concentration by non-invasive ATR-FT-IR-Spectroscopy, Cell. Mol. Biol. 44 (1998) 899-912.

[49] S. Argov, J. Ramesh, A. Salman, J. Goldstein, I. Sinelnikov, H. Guterman, S. Mordechai, Inflammatory bowel diseases as an intermediate stage between normal and cancer: a FTIR-microspectroscopy approach, J. Biomed Optics 7 (2002) 1-7.

[50] S. Argov, R.K. Sahu, E. Bernshtain, A. Salman, G. Shohat, U. Zelig, S. Mordechai, Inflamatory bowel diseases as an intermediate stage between normal and cancer: a FTIR-microspectroscopy approach, Biopolymers 75 (2004) 384-392.

[51] D.C. Malins, N.L. Polissar, S.J. Gunselman, Models of DNA structure achieve almost perfect discrimination between normal prostate, benign prostatic hyperplasia 
(BPH), and adenocarcinoma and have a high potential for predicting $\mathrm{BPH}$ and prostatecancer, Proc. Natl. Acad. Sci. U. S. A. 94 (1997) 259-264.

[52] D.C. Malins, P.M. Johnson, E.A. Barker, N.L. Polissar, T.M. Wheeler, K.M. Anderson, Cancer-related changes in prostate DNA as men age and early identification of metastasis in primary prostate tumors, Proc. Natl. Acad. Sci. U. S. A. 100 (2003) 5401-5406.

[53] C. Petibois, G. Deleris, Chemical mapping of tumor progression by FT-IR imaging: towards molecular histopathology, Trends Biotechnol 24 (2006) 455-462.

[54] E. Giorgini, P. Balercia, C. Conti, P. Ferraris, S. Sabbatini, C. Rubini, G. Tosi, Insights on diagnosis of oral cavity pathologies by infrared spectroscopy: a review, J. Mol. Struct. 1051 (2013) 226-232.

[55] S. Sabbatini, C. Conti, C. Rubini, V. Librando, G. Tosi, E. Giorgini, Infrared microspectroscopy of oral squamous cell carcinoma: spectral signatures of cancer grading, Vib. Spectrosc. 68 (2013) 196-203.

[56] E. Lipiec, J. Kowalska, J. Lekki, A. Wiecheć, W.M. Kwiatek, FTIR microspectroscopy in studies of DNA damage induced by proton microbeam in single PC-3 cells, Acta Phys. Pol. A 121 (2011) 506-509.

[57] G.I. Dovbeshko, V.I. Chegel, N.Y. Gridina, O.P. Repnytska, Y.M. Shirshov, V.P. Tryndiak, I.M. Todor, G.I. Solyanik, Surface enhanced IR absorption of nucleic acids from tumor cells: FTIR reflectance study, Biopolymers 67 (6) (2002) 470-486.

[58] H.M. Heise, L. Cocchieri, T. Vahlsing, D. Ihrig, J. Elm, Monitoring of interstitial buffer systems using micro-dialysis and infrared spectrometry, Proc. SPIE 10072 (2017), 100720E-1-100720E-14.
[59] A. Borg, D. Birkhed, Secretion of glucose in human parotid saliva after carbohydrate intake, Scand. J. Dent. Res. 96 (1988) 551-556.

[60] M. Khajehpour, J.L. Dashnau, J.M. Vanderkooi, Infrared spectroscopy used to evaluate glycosylation of proteins, Anal. Biochem. 348 (2006) 40-48.

[61] P.D.V. de Almeida, A.M.T. Grégio, M.Â.N. Machado, A.A.S. de Lima, L.R. Azevedo, Saliva composition and functions: a comprehensive review, J. Contemp. Dent. Pract. 9 (2008) 072-080.

[62] W. Yang, X. Xiao, J. Tan, Q. Cai, In situ evaluation of breast cancer cell growth with 3D ATR-FTIR spectroscopy, Vib. Spectrosc. 49 (2009) 64-67.

[63] D.C. Malins, V.M. Green, T.M. Wheeler, E.A. Barker, M.A. Vinson, M. Sayeeduddin, K.E. Hellstrom, K.M. Anderson, Metastatic cancer DNA phenotype identified in normal tissues surrounding metastasizing prostate carcinomas, Proc. Natl. Acad. Sci. U. S. A. 101 (2004) 11428-11431.

[64] R. Eckel, H. Huo, H.W. Guan, X. Hu, X. Che, W.D. Huang, Characteristic infrared spectroscopic patterns in the protein bands of human breast cancer tissue, Vib. Spectrosc. 27 (2001) 165-173.

[65] Y. Kim, C.A. Rose, Y. Liu, Y. Ozaki, G. Datta, A.T. Tu, FTIR and near-infrared FT-Raman studies of the secondary structure of insulinotropin in the solid state: $\alpha$-helix to $\beta$ sheet conversion induced by phenol and/or high shear force, J. Pharm. Sci. 83 (1994) 1175-1180. 